\title{
Cinémas
}

Revue d'études cinématographiques

Journal of Film Studies

\section{Dont acte}

\section{Gilles Thérien}

Volume 9, numéro 2-3, printemps 1999

Les Scénarios fictifs

URI : https://id.erudit.org/iderudit/024782ar

DOI : https://doi.org/10.7202/024782ar

Aller au sommaire du numéro

\section{Éditeur(s)}

Cinémas

ISSN

1181-6945 (imprimé)

1705-6500 (numérique)

Découvrir la revue

Citer ce document

Thérien, G. (1999). Dont acte. Cinémas, 9(2-3), 7-7.

https://doi.org/10.7202/024782ar d'utilisation que vous pouvez consulter en ligne.

https://apropos.erudit.org/fr/usagers/politique-dutilisation/ 


\section{Dont acte}

On le sait ou on s'en doute, une revue ne naît pas du hasard. C'est vrai pour toutes les revues du monde académique et c'est encore plus vrai dans le domaine des études cinématographiques où il faut penser images en même temps que texte, discipline et public lecteur. La revue Cinémas publie depuis 1990 et ce numéro est le dernier du volume 9. C'est dire 27 numéros, dont 8 doubles, des collaborations nombreuses du Québec et du Canada, des États-Unis, d'Europe et d'Asie. Tout cela aurait été impossible sans une collaboration efficace à tous les niveaux.

Les deux fondateurs de Cinémas, Michel Larouche et Denise Pérusse, ont d'abord travaillé au projet d'une revue avant d'en lancer la production, cela avant 1990. Depuis, sous la direction de Michel Larouche, entouré de son comité de direction, d'un comité de rédaction très élargi et de gentils lecteurs, la revue a fait ses premiers pas dans des couleurs et une présentation dont nous sommes très fiers, supervisée par Claude Ladouceur. Les organismes subventionneurs tant à Québec qu'à Ottawa ont rapidement aidé Cinémas. Aujourd'hui, la revue a son lectorat spécialisé, elle possède son site Web où on peut consulter les articles des numéros épuisés et les résumés des autres. Quand on regarde l'importance du domaine qu'elle a permis d'explorer durant toutes ces années et la façon dont elle s'est acquittée de sa tâche, on peut penser "mission accomplie". C'est sur cette note de satisfaction que Michel Larouche passe la main à André Gaudreault qui dirigera la revue à compter du volume 10 avec une équipe renouvelée.

Merci aux ouvriers de la première heure, bienvenue aux autres!

Gilles Thérien, membre des comités de direction et de rédaction 